\title{
Evaluation of the impact of fibromyalgia in disease activity and treatment effect in spondyloarthritis
}

\author{
Natalia Bello ${ }^{1,2}$, Adrien Etcheto ${ }^{1,3}$, Caroline Béal ${ }^{1}$, Maxime Dougados ${ }^{1,3}$ and Anna Moltó ${ }^{1,3^{*}}$
}

\begin{abstract}
Background: Fibromyalgia (FM) can coexist with Spondyloarthritis (SpA) leading to diagnostic and treatment dilemmas, especially in the presence of enthesitis. With this study we aimed to estimate the prevalence of FM in SpA and to compare the clinical/disease features and TNF inhibitors (TNFi) in patients with/without FM.

Method: FM was defined by a score $=>5 / 6$ of the Fibromyalgia Rapid Screening Tool (FiRST). SpA patients (according to the rheumatologist) and consecutively consulting in the day care hospital but also in the outpatient clinic at the rheumatology department of a tertiary care university hospital were included.

Demographics, disease characteristics, activity and severity and TNFi treatment were compared in patients with and without FM; retention rate of the first TNFi and associated factors were explored (Kaplan Meier and Cox regression).

Results: Of the 196 enrolled SpA patients, 42 (21.4\%) were positively screened for FM. No statistically significant differences in the prevalence of FM were found with regard to the fulfillment of the ASAS criteria for peripheral/ axial SpA, nor with regard to the fulfillment of the imaging vs. clinical arm of the ASAS criteria. However, patients with coexisting FM presented significantly with more enthesitis, higher disease activity (BASDAI and VAS) and poorer function scores (BASFI). No differences were found with regard to the initiation of TNFi treatment ( $79.0 \% \mathrm{vs}$. $70.0 \%$, respectively), but the retention rate of the first TNFi after 2 years was shorter in the group of patients with FM (28.1\% (95\% Cl 12.5-44.0) vs. $41.7 \%$ (95\% Cl 32.2-51.3), $p=0.01)$.

Conclusion: This study confirms that coexistent FM in SpA might impact the patient-reported outcome indices for disease activity and function, and the retention rate of TNFi treatment.
\end{abstract}

Keywords: Spondyloarhtritis, Fibromyalgia, TNF alpha blockers treatment

\section{Background}

Spondyloarthritis (SpA) is a disease that includes a spectrum of chronic inflammatory entities involving the axial skeleton (sacroiliac joints and spine) and the peripheral joints, and sharing a number of clinical features such as arthritis, enthesitis, uveitis, dactylitis, psoriasis, and inflammatory bowel disease with a common genetic background, the human leukocyte antigen (HLA) B27 [1-4]. In 2009, the Assessment of the Spondyloarthritis International Society (ASAS) proposed a new set of classification criteria with the aim of recognizing patients

\footnotetext{
* Correspondence: anna.molto@aphp.fr

${ }^{1}$ Rheumatology Department, Cochin Hospital, AP-HP, París, France

${ }^{3}$ INSERM (U1153): Clinical Epidemiology and Biostatistics, PRES Sorbornne

Paris-Cité, Paris, France

Full list of author information is available at the end of the article
}

with early axial SpA (axSpA) including for the first time the imaging of the sacroiliac joints (SIJ) by magnetic resonance imaging (MRI) and abnormal C-reactive protein (CRP) [5], and another set for SpA patients with predominantly peripheral manifestations (e.g., peripheral arthritis, enthesitis, and dactylitis) [6, 7]. The axSpA criteria allow the classification of patients with chronic back pain lasting for $\geq 3$ months and occurring before 45 years of age, through two arms: the imaging arm in which patients present with sacroiliitis (either on radiographs or MRI) plus at least one additional SpA feature, and the clinical arm in which patients need to be HLA-B27 positive and present with two or more SpA characteristics.

However, the clinical arm has been criticized and is not well-recognized by our health authorities nor some 
colleagues, despite the fact that it has been fully validated [8]. The main argument for such criticism is that this arm would allow the classification of SpA in patients without any objective sign of inflammation (abnormal CRP or presence of inflammatory lesions seen on MRI of the SIJ) or structural damage in the SIJ seen on pelvic radiographs $[6,9]$.

Indeed, although the ASAS criteria have been proven to be highly specific with acceptable sensitivity both for diagnosis and classifying SpA patients $[10,11]$, one could consider it inappropriate to apply them as a diagnostic tool in the absence of objective signs of structural damage or inflammation, due to the potential risk of misdiagnosing or over-diagnosing SpA in patients with other conditions (e.g., fibromyalgia (FM), especially in the presence of enthesitis [12].

FM is a complex chronic condition of unknown etiology being considered as a pain amplification syndrome associated with a central nervous system sensitization mechanism [13]. Its hallmark symptoms are chronic widespread musculoskeletal pain and generalized tender points, but other symptoms can be present, such as fatigue, sleep alterations and stiffness leading to significant physical disability and reduced quality of life $[14,15]$. Its prevalence has been estimated at around $2-7 \%$ of the general global population and is predominantly found in women [13]. FM can frequently be associated with other rheumatic diseases such as rheumatoid arthritis and Sjögren syndrome [16], and some studies have reported the prevalence of FM at $12.6-15.0 \%$ in SpA, but studies are sparse [16-18]. This FM-SpA association may present diagnostic and treatment dilemmas because some SpA symptoms (e.g., pain at entheses, fatigue, stiffness, and tenderness) can be also found in FM [12, 19]. Few data are available to date, but it has already been reported that SpA patients with FM tend to present with higher self-reported disease activity indices (i.e., Bath Ankylosing Spondylitis Disease Activity Index (BASDAI)) making interpretation of disease activity and treatment response in SpA patients with concomitant FM very challenging [19-21].

In the absence of specific biomarkers for FM, diagnosis can currently be performed using the American College of Rheumatology (ACR) criteria (1990 ACR classification of FM and the ACR 2010 and modified 2010 diagnostic criteria (2011)) [14, 22, 23]. However, these criteria were developed for research and classification purposes, and are difficult to apply in daily practice because they are time consuming and require some training to be implemented [24]. Moreover, such criteria (i.e., ACR 1990) integrate tender points on physical examination that might reflect enthesitis in patients with SpA. Therefore, with the objective of identifying an easy and valid screening tool to facilitate the identification of FM patients in clinical practice and research, the self-reported Fibromyalgia Rapid Screening Tool (FiRST) [25] was developed, which has sensitivity of $90.5 \%$ and specificity of $85.7 \%$ [25] for the identification of FM patients.

All the above prompted us to conduct this study aiming to 1) estimate the prevalence of FM according to the FiRST in a population of patients with SpA and to compare the prevalence with regard to the arm fulfilled within the axial criteria (i.e., the imaging and clinical arms), and 2) compare the demographics/disease features, and TNF inhibitor (TNFi) treatment in terms of initiation and first TNFi retention rate, in patients with and without FM, respectively.

\section{Methods \\ Study design}

The completion of the FiRST, BASDAI and Bath Ankylosing Spondylitis Functional Index (BASFI) questionnaires were performed prospectively, and data on demographics and disease features were retrospectively retrieved from the medical files.

\section{Study population}

Patients aged $\geq 18$ years were included, who were diagnosed with SpA (according to the rheumatologist) and were consecutively attending the day care hospital, but also the outpatient clinic at the rheumatology department of a tertiary care university hospital.

\section{Data collection}

FM was defined if the score was $\geq 5 / 6$ in the FIRST questionnaire [25]. Medical files of each patient who completed the FiRST questionnaire were reviewed by two external investigators. The following information was collected: age, gender, smoking status (past, current, never), body weight and height, and the date of SpA diagnosis, all available items permitting the calculation of the fulfilment of the ASAS criteria; BASDAI [26], global visual analog scale (VAS) according to the patient, presence and number of current swollen joints diagnosed by a physician and CRP at the day of the visit were collected, and severity of the disease evaluated at the time of the visit using the BASFI [27]; SpA treatments since disease onset including information on non-steroidal anti-inflammatory drugs (NSAIDs), conventional diseasemodifying antirheumatic drugs (cDMARD), and the type and number of TNFi, number of switches, start/end date and reason for discontinuation for each TNFi. Information on past or current use of psychotropic medications (i.e., myorelaxants, antidepressants, or anxiolytics), strong opioids [28, 29], and history of depression were collected. No imaging (i.e., ultrasound or MRI) was performed specifically for this study. 


\section{Ethics considerations}

This study was not submitted to any ethical committee because it was performed using data collected in routine care. However, all patients gave their oral consent to use their data for this present study (as stated by French national official procedures for non-interventional studies).

\section{Missing data handling}

In the case of missing information patients were contacted by telephone to obtain such information. If CRP was not available on the day of the visit, the last available CRP measurement collected within the previous 6 months was used. Furthermore, if any of the answers to the FiRST questionnaire were missing, we only excluded the patients for whom the missing answers did not allow us to determine their group (with/without FM), e.g., a patient who positively answered three questions but did not answer the last three questions.

\section{Statistical analysis}

Continuous variables were reported by their mean and standard deviation (SD) and qualitative variables by frequency and percentage. Statistical significance was set at $p<0.05$. The analysis was performed with the statistical software SAS 9.4.

Evaluation of the reliability of the FiRST questionnaire was performed. It was evaluated in a subset of 22 patients in two consecutive visits. These patients had stable disease ( BASDAI between two visits: $0.22( \pm 1.32)$ ) and no treatment changes. The average time between the two visits was 22 weeks $( \pm 7.68)$. Reliability of the FM diagnosis according to the FiRST definition was assessed by prevalence-adjusted bias-adjusted kappa statistics (PABAK).

FM prevalence was estimated in the global SpA population, but also with regard to the ASAS classification criteria fulfilment (axial or peripheral) and to the fulfilment of the imaging vs. clinical arm of the ASAS criteria for axSpA. Demographics, disease characteristics, activity and severity were compared in the FM+/FM- groups by the $t$ test and chi square $\left(\mathrm{X}^{2}\right)$ test, as appropriate.

The percentage of patients who were ever exposed to a TNFi, the mean number of TNFi received, the mean duration of the first TNFi treatment and the reasons for discontinuation of each TNFi were assessed in the total population and compared in the $\mathrm{FM}+/ \mathrm{FM}-$ groups. The retention rate of the first TNFi treatment in the FM+/FM- groups was estimated by survival analysis (Kaplan-Meier curves) and compared by the log-rank test. The predisposing factors for discontinuation of the first TNFi during the first 2 years were estimated by Cox regression models first by univariate and thereafter by multivariate analysis, including in the model only the variables that had a $p$ value $<0.10$ in the univariate analysis, plus age and gender. Finally, the percentage of patients who received $\geq 3$ TNFi within 12 months (switchers) in both groups was compared by the $\chi^{2}$ test.

\section{Results}

Of the 213 patients who completed the FiRST questionnaire, 196 were retained for our analysis: patients without a confirmed diagnosis of SpA $(n=14)$ and patients who incompletely answered the questionnaire $(n=3)$ were excluded. The reliability of the FM diagnosis was good, with a PABAK $=0.64$ (95\% CI 0.314; 0.958). In our SpA population, the prevalence of concomitant FM was $21.4 \%(42 / 196)$.

\section{Fibromyalgia prevalence according to the ASAS classification criteria}

Figure 1 summarizes the prevalence of FM depending on the ASAS classification criteria. Of the 196 patients included in the analysis, $185(94.4 \%)$ met the ASAS criteria (182 (98.4\%) and 3 (1.6\%) axial and peripheral, respectively). For the ASAS criteria for axSpA, 150 patients $(82.4 \%)$ and 32 patients $(17.6 \%)$ fulfilled the imaging and clinical arms, respectively.

Prevalence of concomitant FM was greater in the group of patients not fulfilling the ASAS criteria, although this difference was not statistically significant (21.1 \% vs. $30.0 \%$, not significant). More interestingly, no differences in the prevalence of FM were observed in the group of patients fulfilling the imaging and clinical arms of the ASAS criteria for axSpA (21.3 \% vs. $19 \%$, not significant).

Demographics, disease characteristics, activity and severity were compared in the FM+ and FM- groups (see Table 1). These two groups were similar in terms of age, mean age at disease onset and smoking status. However, patients fulfilling the FM+ definition presented more frequently with enthesitis (59.5\% vs. $39.0 \%, p=0.01)$, a higher total BASDAI $(4.7( \pm 2.3)$ vs. $2.6( \pm 1.9), p<0.01)$, higher global VAS $(5.9( \pm 2.4)$ vs. $3.0( \pm 2.5), p<0.01)$ and higher BASFI $(4.8( \pm 2.7)$ vs. $2.0( \pm 2.3), p<0.01)$. No significant differences were found for treatment with nonsteroidal anti-inflammatory drugs (NSAIDs) and conventional disease-modifying antirheumatic drugs (cDMARDs); as expected, the percentage of patients with either history of depression, or use of psychotropic medication or strong opioids was significantly higher in the FM+ group (67 \% vs. $35 \%, p<0.01)$.

\section{TNFi treatment}

Table 2 summarizes TNFi treatment characteristics in our population. The percentage of patients ever exposed to TNFi did not differ between the FM+ vs. FM- groups (79\% vs. $70 \%$, respectively, not significant), whereas the percentage of switchers was significantly higher in the 


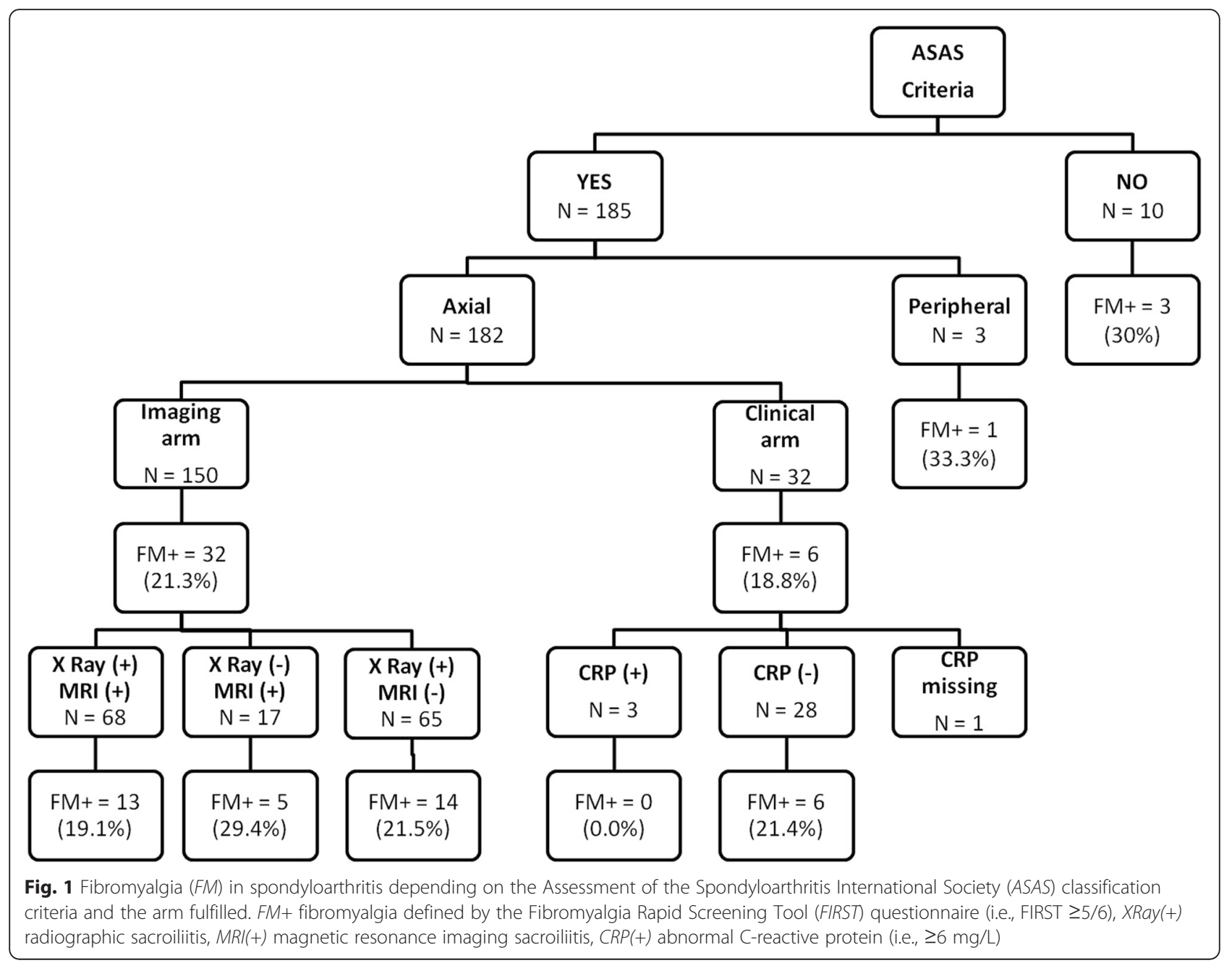

FM+ group (15.2 \% vs. $4.0 \%, p=0.03)$. Mean duration of the first TNFi was significantly shorter in the FM+ group $(1.7( \pm 2.4)$ vs. $3.5( \pm 4.0)$ years, $p<0.01)$ (Table 2$)$.

The retention rate of the first TNFi after 2 years was significantly shorter in the FM+ group: $28.1 \%$ (95 \% CI $12.5 ; 44.0)(\mathrm{n}=9)$ vs. $41.7 \%(95 \%$ CI $32.2 ; 51.3)(\mathrm{n}=43)$ of patients were still on TNFi treatment after 2 years in the FM+ and FM- groups, respectively $(p<0.01)$ (Fig. 2).

Univariate Cox analysis identified FM (hazard ratio (HR) 1.8, 95 \% CI 1.1; 3.0), peripheral involvement (HR $1.6,95 \%$ CI $1.0 ; 2.6$ ) and history of depression or psychotropic medications or strong opioids intake (HR 0.6, $95 \%$ CI $0.4 ; 0.9$ ) as associated factors for discontinuation of the first TNFi; however, on multivariate analysis only FM (HR 1.7, 95 \% CI 1.0; 2.9) and peripheral involvement (HR 1.6, 95 \% CI 1.0; 2.6) were independently associated with discontinuation of the first TNFi. Reasons for discontinuation of each TNFi were similar percentages in the two groups ( $p$ value not significant), inefficacy being the most frequent reason in the total population.

\section{Discussion}

To our best knowledge, this is the first study aiming to evaluate the prevalence of FM in a population of patients with SpA with regard to the fulfilment of the ASAS classification criteria, and our results show that no differences were found between the imaging and clinical arms of the ASAS criteria for axSpA. This finding is an argument in favor of the validity of such criteria, particularly for the clinical arm, which is still not fully accepted by some members of the scientific community. The phenotype of SpA patients with concomitant FM was more frequently female and presented more frequently with enthesitis, reporting greater disease activity and poorer function scores. These results are consistent with previous studies $[16,17,20,30,31]$.

As SpA patients with coexisting FM frequently present with a higher disease activity score, the evaluation of disease activity and treatment effect might be challenging, and might lead to unnecessary initiation of a TNFi, dose escalations or switches. In our study, the percentage of patients initiating a TNFi did not differ in the FM+ and 
Table 1 Demographic and disease characteristics of patients with and without fibromyalgia

\begin{tabular}{|c|c|c|c|c|}
\hline & $\begin{array}{l}\text { Total number of patients } \\
(n=196)\end{array}$ & $\begin{array}{l}\text { Fibromyalgiat } \\
(n=42)\end{array}$ & $\begin{array}{l}\text { Fibromyalgia- } \\
(\mathrm{n}=154)\end{array}$ & $P$ \\
\hline Age, years & $43.0(12.6)$ & $41.4(10.2)$ & $43.4(13.13)$ & 0.21 \\
\hline Gender, female & $59(30.1 \%)$ & $17(40.5 \%)$ & $42(27.3 \%)$ & 0.10 \\
\hline Age at disease onset, years & $29.9(11.9)$ & $28.7(9.3)$ & $30.2(12.5)$ & 0.40 \\
\hline Smoking status, ever smoked & $106(55.8 \%)$ & $23(56.1 \%)$ & $83(55.7 \%)$ & 0.96 \\
\hline HLA B27-positive & $157(82.2 \%)$ & 35 (83.3 \%) & $122(81.9 \%)$ & 0.83 \\
\hline Radiographic sacroiliitis & 134 (70.2 \%) & $27(67.5 \%)$ & $107(70.9 \%)$ & 0.68 \\
\hline $\begin{array}{l}\text { Magnetic resonance imaging evidence of } \\
\text { inflammatory lesions of the sacroiliac joints }\end{array}$ & $88(58.3 \%)$ & $20(54.1 \%)$ & $68(59.7 \%)$ & 0.55 \\
\hline Raised C-reactive protein* & $39(22.3 \%)$ & $8(20.0 \%)$ & $31(23.0 \%)$ & 0.69 \\
\hline Past history of, or current arthritis & $72(36.7 \%)$ & $12(28.6 \%)$ & 60(39\%) & 0.22 \\
\hline Past history of, or current enthesitis & $85(43.4 \%)$ & $25(59.5 \%)$ & 60 (39 \%) & 0.01 \\
\hline $\begin{array}{l}\text { Bath Ankylosing Spondylitis Disease } \\
\text { Activity Index total (0-10) }\end{array}$ & $3.0(2.2)$ & $4.7(2.3)$ & $2.6(1.9)$ & $<0.01$ \\
\hline Global visual analog scale (0-10) & $3.6(2.8)$ & $5.9(2.4)$ & $3.0(2.5)$ & $<0.01$ \\
\hline $\begin{array}{l}\text { Bath Ankylosing Spondylitis Functional } \\
\text { Index (range 0-10) }\end{array}$ & $2.6(2.7)$ & $4.8(2.7)$ & $2.0(2.3)$ & $<0.01$ \\
\hline History of depression & $42(23.2 \%)$ & $16(41.0 \%)$ & $26(18.3 \%)$ & $<0.01$ \\
\hline $\begin{array}{l}\text { Past or current intake of psychotropic } \\
\text { medications** or strong opioids }\end{array}$ & $82(41.8 \%)$ & $28(66.7 \%)$ & $54(35.1 \%)$ & $<0.01$ \\
\hline $\begin{array}{l}\text { Past or current intake of psychotropic medications } \\
\text { or strong opioids or history of depression }\end{array}$ & $82(41.8 \%)$ & $28(66.7 \%)$ & $54(35.1 \%)$ & $<0.01$ \\
\hline Non-steroidal anti-inflammatory drug intake, ever & $193(99.0 \%)$ & $42(100.0 \%)$ & $151(98.7 \%)$ & 1.00 \\
\hline Synthetic disease-modifying antirheumatic drug use, ever & $104(53.1 \%)$ & $23(54.8 \%)$ & $81(52.6 \%)$ & 0.80 \\
\hline
\end{tabular}

All results are presented as mean \pm SD for continuous variables or number (\%) for categorical variables. Fibromyalgia + was defined as a Fibromyalgia Rapid Screening Tool (FiRST) score $\geq 5 / 6$. ${ }^{*} \geq 6 \mathrm{mg} / \mathrm{L} ;{ }^{* *}$ myorelaxants, antidepressants or anxiolytics

FM- group, but patients with concomitant FM+ disease were more likely to switch to other TNFi treatments. Moreover, the retention rate of the first TNFi was shorter in the FM+ group and the presence of FM was independently associated with a first TNFi discontinuation. This confirms that the existence of concomitant FM in SpA might complicate the evaluation of treatment response $[19,20]$, and suggests that coexistence of FM should be carefully screened when initiating a TNFi and/or evaluating its treatment effect, especially in the presence of

Table 2 TNF inhibitor (TNFi) treatment in patients with and without fibromyalgia

\begin{tabular}{|c|c|c|c|c|}
\hline & $\begin{array}{l}\text { Total number of patients } \\
(n=196)\end{array}$ & $\begin{array}{l}\text { Fibromyalgia+ } \\
(n=42)\end{array}$ & $\begin{array}{l}\text { Fibromyalgia- } \\
(n=154)\end{array}$ & $P$ \\
\hline Patients who received at least one TNFi & $141(71.9 \%)$ & $33(78.6 \%)$ & $108(70.1 \%)$ & 0.28 \\
\hline Number of TNFi treatments & $1.84(1.0)$ & $2.36(1.1)$ & $1.68(0.9)$ & $<0.01$ \\
\hline Switchers* & $9(6.5 \%)$ & $5(15.2 \%)$ & $4(3.8 \%)$ & 0.03 \\
\hline \multicolumn{5}{|l|}{ First TNFi } \\
\hline Mean duration of first TNFi treatment, years & $3.0(3.8)$ & $1.7(2.4)$ & $3.5(4.0)$ & $<0.01$ \\
\hline \multicolumn{5}{|l|}{ Reason for TNFi discontinuation: } \\
\hline Inefficacy \% & $54(69.2 \%)$ & $12(54.6 \%)$ & $42(75.0 \%)$ & 0.14 \\
\hline Toxicity \% & $4(5.1 \%)$ & $2(9.1 \%)$ & $2(3.6 \%)$ & 0.76 \\
\hline Inefficacy + toxicity $\%$ & $4(5.1 \%)$ & $3(13.6 \%)$ & $1(1.8 \%)$ & 0.23 \\
\hline Others \% & $16(20.5 \%)$ & $5(22.7 \%)$ & $11(19.6 \%)$ & 1.00 \\
\hline
\end{tabular}

All results are presented as mean \pm SD for continuous variables or number (\%) for categorical variables. Fibromyalgia + was defined as a Fibromyalgia Rapid Screening Tool (FiRST) score $\geq 5 / 6$. *Patients who received $\geq 3$ TNFi within $\leq 12$ months 


\section{Retention rate for the first TNFi}

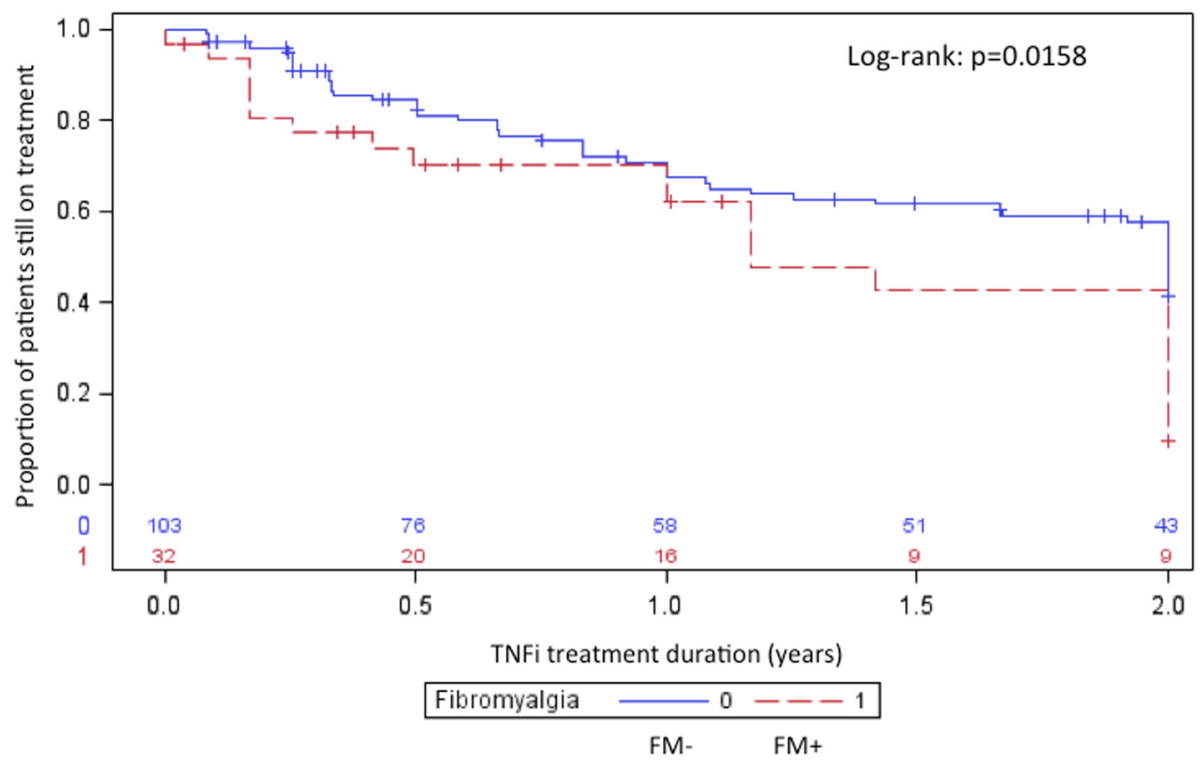

Fig. 2 Kaplan-Meier curve for retention rate of first TNF inhibitor (TNFi) during the first 2 years. FM fibromyalgia

peripheral and/or enthesitic symptoms and in the presence of very severe disease activity and patient-reported scores. In this sense the FiRST questionnaire represents an easy to use and valid tool that might be used in clinical practice before starting a TNFi, in particular in patients presenting with enthesitis.

Our study has some weaknesses but also some strengths. First the diagnosis of FM according to the rheumatologist was not collected. However, we verified the external validity of the FiRST in this SpA setting by confirming the greater use of psychotropic medication or strong opioids, or the history of depression in the group of patients positively screened as FM+ $[32,33]$. Second, lower sensitivity of the FIRST when applied in an SpA population compared to the original study (66\% vs. $90 \%$ ) has been recently reported [34]; however, these data were not available at the time the study started. Furthermore we did not use the ACR criteria (1990 ACR classification of FM [14] - modified 2010 preliminary ACR criteria [22]) to validate our results on the prevalence of FM, but this was due to the complexity of applying such criteria in a daily practice setting [23]. Finally, one could consider that the sample size of our study was too small to draw definite conclusions, e.g., in the evaluation of the retention rate of the first TNFi, only nine patients were at risk after 18 months of follow up in the FM+ group.

Nevertheless, our study also has some strengths. First, our analyses were performed on a representative number of SpA patients in daily practice. Furthermore, to the best of our knowledge this is the first study aiming to evaluate the prevalence of FM according to the fulfilment of the ASAS classification criteria and its impact on TNFi treatment.

\section{Conclusions}

In summary, the similar percentages of FM in the different subgroups of the ASAS classification criteria might be a good argument in favor of the validity of these criteria, and in particular of the clinical arm. The coexistence of FM might impact the score of the instrument used to evaluate disease activity and severity, particularly in the patient-reported scores, and therefore might complicate the evaluation of treatment response. The implementation of the FiRST questionnaire might be helpful in clinical practice, especially in the presence of enthesitic symptoms. Other studies aiming to prospectively evaluate the impact of concomitant FM in SpA in the treatment effect of TNFi should allow us to confirm (or not) our findings.

\section{Abbreviations \\ ACR: American College of Rheumatology; ASAS: Assessment of Spondyloarthritis International Society; axSpA: axial SpA; BASDAl: Bath Ankylosing Spondylitis Disease Activity Index; BASFI: Bath Ankylosing Spondylitis Functional Index; CDMARD: conventional disease-modifying antirheumatic drug; CRP: C-reactive protein; FiRST: Fibromyalgia Rapid Screening Tool; FM: fibromyalgia; MRI: magnetic resonance imaging; NSAID: non-steroidal anti-inflammatory drug; PABAK: prevalence-adjusted bias-adjusted kappa statistics; SIJ: sacroiliac joint; SpA: spondyloarthritis; \\ TNFi: tumor necrosis factor inhibitor; VAS: visual analog scale.}

\section{Competing interests}

There are no other benefits from commercial sources for the work reported in the manuscript, and no other financial/non-financial interests that any of the authors may have, which could create a potential conflict of interest or the appearance of a conflict of interest with regard to the work. 


\section{Authors' contributions}

NB participated in the design of the study, data collection, design of the statistical analysis plan and drafted the manuscript. CB participated in data collection and critically reviewed the manuscript. AE participated in the design of the study and performed the statistical analysis and critically reviewed the manuscript. MD conceived the study, participated in the interpretation of data and critically reviewed the manuscript. AM conceived the study, participated in the interpretation of data, contributed to drafting the manuscript and critically reviewed it. All authors have given final approval of the version to be published and have agreed to be accountable for all aspects of the work in ensuring that questions related to the accuracy or integrity of any part of the work are appropriately investigated and resolved.

\section{Acknowledgements}

NB received a bursary for stays abroad from Sociedad Española de Reumatologia to conduct this study.

\section{Author details}

'Rheumatology Department, Cochin Hospital, AP-HP, París, France. ${ }^{2}$ Rheumatology Department, Hospital General Universitario Gregorio Marañón, Madrid, Spain. ${ }^{3}$ INSERM (U1153): Clinical Epidemiology and Biostatistics, PRES Sorbornne Paris-Cité, Paris, France.

\section{Received: 22 September 2015 Accepted: 29 January 2016}

\section{Published online: 09 February 2016}

\section{References}

1. Ehrenfeld M. Spondyloarthropathies. Best Pract Res Clin Rheumatol. 2012;26:135-45.

2. Garg N, van den Bosch F, Deodhar A. The concept of spondyloarthritis: Where are we now? Best Pract Res Clin Rheumatol. 2014;28:663-72.

3. Gladman DD. Clinical aspects of the spondyloarthropathies. Am J Med Sci. 1998;316:234-8.

4. Dougados M. Diagnostic features of ankylosing spondylitis. Br J Rheumatol. 1995;34:301-3.

5. Rudwaleit M, van der Heijde D, Landewé R, Listing J, Akkoc N, Brandt J, et al. The development of Assessment of SpondyloArthritis international Society classification criteria for axial spondyloarthritis (part II): validation and final selection. Ann Rheum Dis. 2009;68:777-83.

6. Dougados M, Baeten D. Spondyloarthritis. Lancet. 2011;377:2127-37.

7. Rudwaleit M, van der Heijde D, Landewé R, Akkoc N, Brandt J, Chou CT, et al. The Assessment of SpondyloArthritis International Society classification criteria for peripheral spondyloarthritis and for spondyloarthritis in general. Ann Rheum Dis. 2011;70:25-31.

8. Moltó A, Paternotte S, van der Heijde D, Claudepierre P, Rudwaleit M, Dougados M. Evaluation of the validity of the different arms of the ASAS set of criteria for axial spondyloarthritis and description of the different imaging abnormalities suggestive of spondyloarthritis: data from the DESIR cohort. Ann Rheum Dis. 2015;74(4):746-51.

9. Sieper J, Rudwaleit M, Baraliakos X, Brandt J, Braun J, Burgos-Vargas R, et al. The Assessment of SpondyloArthritis international Society (ASAS) handbook: a guide to assess spondyloarthritis. Ann Rheum Dis. 2009;68 Suppl 2:ii1-44.

10. Moltó A, Paternotte S, Comet D, Thibout E, Rudwaleit M, Claudepierre P, et al. Performances of the Assessment of SpondyloArthritis International Society axial spondyloarthritis criteria for diagnostic and classification purposes in patients visiting a rheumatologist because of chronic back pain: results from a multicenter, cross-sectional study. Arthritis Care Res. 2013:65:1472-81.

11. Tomero E, Mulero J, de Miguel E, Fernández-Espartero C, Gobbo M, Descalzo MA, et al. Performance of the Assessment of Spondyloarthritis International Society criteria for the classification of spondyloarthritis in early spondyloarthritis clinics participating in the ESPERANZA programme. Rheumatol (Oxford). 2014;53:353-60.

12. Roussou E, Ciurtin C. Clinical overlap between fibromyalgia tender points and enthesitis sites in patients with spondyloarthritis who present with inflammatory back pain. Clin Exp Rheumatol. 2012;30(6 Suppl 74):24-30.

13. Yunus MB. The prevalence of fibromyalgia in other chronic pain conditions. Pain Res Treat. 2012;2012:584573.
14. Wolfe F, Smythe HA, Yunus MB, Bennett RM, Bombardier C, Goldenberg DL, et al. The American College of Rheumatology 1990 Criteria for the Classification of Fibromyalgia. Report of the Multicenter Criteria Committee. Arthritis Rheum. 1990:33:160-72.

15. Atzeni F, Salli S, Benucci M, Di Franco M, Alciati A, Sarzi-Puttini P. Fibromyalgia and arthritides. Reumatismo. 2012;64:286-92.

16. Haliloglu S, Carlioglu A, Akdeniz D, Karaaslan Y, Kosar A. Fibromyalgia in patients with other rheumatic diseases: prevalence and relationship with disease activity. Rheumatol Int. 2014;34:1275-80.

17. Salaffi F, De Angelis R, Carotti M, Gutierrez M, Sarzi-Puttini P, Atzeni F. Fibromyalgia in patients with axial spondyloarthritis: epidemiological profile and effect on measures of disease activity. Rheumatol Int. 2014;34:1103-10.

18. Azevedo VF, Paiva E dos S, Felippe LRH, Moreira RA. Occurrence of fibromyalgia in patients with ankylosing spondylitis. Rev Bras Reumatol. 2010:50:646-50.

19. Atzeni F, Boccassini L, Di Franco M, Alciati A, Marsico A, Cazzola M, et al. Chronic widespread pain in spondyloarthritis. Reumatismo. 2014;66:28-32.

20. Aloush V, Ablin JN, Reitblat T, Caspi D, Elkayam O. Fibromyalgia in women with ankylosing spondylitis. Rheumatol Int. 2007;27:865-8.

21. Marchesoni A, Atzeni F, Spadaro A, Lubrano E, Provenzano G, Cauli A, et al. Identification of the clinical features distinguishing psoriatic arthritis and fibromyalgia. J Rheumatol. 2012:39:849-55.

22. Wolfe F, Clauw DJ, Fitzcharles M-A, Goldenberg DL, Katz RS, Mease P, et al. The American College of Rheumatology preliminary diagnostic criteria for fibromyalgia and measurement of symptom severity. Arthritis Care Res. 2010:62:600-10

23. Bennett RM, Friend R, Marcus D, Bernstein C, Han BK, Yachoui R, et al. Criteria for the diagnosis of fibromyalgia: validation of the modified 2010 preliminary American College of Rheumatology criteria and the development of alternative criteria. Arthritis Care Res. 2014:66:1364-73.

24. Wolfe F. Stop using the American College of Rheumatology criteria in the clinic. J Rheumatol. 2003;30:1671-2.

25. Perrot S, Bouhassira D, Fermanian J, Cercle d'Etude de la Douleur en Rhumatologie. Cercle d'Etude de la Douleur en Rhumatologie. Development and validation of the Fibromyalgia Rapid Screening Tool (FiRST). Pain. 2010;150:250-6.

26. Garrett S, Jenkinson T, Kennedy LG, Whitelock H, Gaisford P, Calin A. A new approach to defining disease status in ankylosing spondylitis: the Bath Ankylosing Spondylitis Disease Activity Index. J Rheumatol. 1994;21:2286-91.

27. Calin A, Garrett S, Whitelock H, Kennedy LG, O'Hea J, Mallorie P, et al. A new approach to defining functional ability in ankylosing spondylitis: the development of the Bath Ankylosing Spondylitis Functional Index. J Rheumatol. 1994;21:2281-5.

28. Jadad AR, Browman GP. The WHO analgesic ladder for cancer pain management. Stepping up the quality of its evaluation. JAMA. 1995;274: 1870-3.

29. World Health Organization. WHO's cancer pain ladder for adults. http://www. who.int/cancer/palliative/painladder/en/.

30. Heikkilä S, Ronni S, Kautiainen HJ, Kauppi MJ. Functional impairment in spondyloarthropathy and fibromyalgia. J Rheumatol. 2002;29:1415-9.

31. Tournadre A, Pereira B, Lhoste A, Dubost JJ, Ristori JM, Claudepierre P, et al. Differences between women and men with recent-onset axial spondyloarthritis: results from a prospective multicenter French cohort. Arthritis Care Res. 2013;65:1482-9.

32. Torta R, Pennazio F, leraci V. Anxiety and depression in rheumatologic diseases: the relevance of diagnosis and management. Reumatismo. 2014;66:92-7.

33. Wasserman RA, Brummett CM, Goesling J, Tsodikov A, Hassett AL. Characteristics of chronic pain patients who take opioids and persistently report high pain intensity. Reg Anesth Pain Med. 2014;39:13-7.

34. Fan A, Pereira B, Tournadre A, Tatar Z, Malochet-Guinamand S, Soubrier M, et al. Evaluation of the Fibromyalgia Rapid Screening Tool (FiRST) Questionnaire to Screen Fibromyalgia Associated with Inflammatory Rheumatic Disease [abstract]. Arthritis Rheumatol. 2015; 67 (suppl 10). http://acrabstracts.org/abstract/evaluation-of-the-fibromyalgia-rapidscreening-tool-first-questionnaire-toscreen-fibromyalgia-associated-withinflammatory-rheumatic-disease/. Accessed date February 6, 2016. 